Review

\title{
Importance of the Role of $\omega-3$ and $\omega-6$ Polyunsaturated Fatty Acids in the Progression of Brain Cancer
}

\author{
Mayra Montecillo-Aguado ${ }^{1,2}$, Belen Tirado-Rodriguez ${ }^{2} \mathbb{E}$, Zhen Tong ${ }^{3,4} \mathbb{0}$, Owen M. Vega ${ }^{4}$, \\ Mario Morales-Martínez ${ }^{2}$, Shaheen Abkenari ${ }^{4}$, José Pedraza-Chaverri ${ }^{5}(\mathbb{D})$ and \\ Sara Huerta-Yepez ${ }^{2,4, *}$ \\ 1 Programa de Doctorado en Ciencias Biomédicas, Facultad de Medicina, Universidad Nacional Autónoma de \\ Mexico (UNAM), Mexico City 04510, Mexico; mayramontecillo@hotmail.es \\ 2 Hospital Infantil de Mexico, Federico Gomez, Unidad de Investigacion en Enfermedades Oncologicas, \\ Mexico City 06720, Mexico; bely_16@hotmail.com (B.T.-R.); ixnergal@gmail.com (M.M.-M.) \\ 3 Molecular Toxicology Interdepartmental Program and Environmental Health Sciences, University of \\ California, Los Angeles, CA 90095, USA; tong0817@g.ucla.edu \\ 4 Department of Pathology \& Laboratory Medicine, University of California, Los Angeles, CA 90095, USA; \\ omvega@ucsd.edu (O.M.V.); shaheenabkenari@gmail.com (S.A.) \\ 5 Departamento de Biología, Facultad de Química, Universidad Nacional Autonoma de Mexico (UNAM), \\ Mexico City 04510, Mexico; pedraza@unam.mx \\ * Correspondence: shuertay@gmail.com; Tel.: +52-(55)-52289917 (ext. 4401); Fax: +52-(55)-44349663
}

Received: 7 May 2020; Accepted: 9 June 2020; Published: 17 June 2020

\begin{abstract}
Brain cancer is one of the most malignant types of cancer in both children and adults. Brain cancer patients tend to have a poor prognosis and a high rate of mortality. Additionally, $20-40 \%$ of all other types of cancer can develop brain metastasis. Numerous pieces of evidence suggest that omega-3-polyunsaturated fatty acids ( $\omega$-PUFAs) could potentially be used in the prevention and therapy of several types of cancer. PUFAs and oxylipins are fundamental in preserving physiological events in the nervous system; it is, therefore, necessary to maintain a certain ratio of $\omega-3$ to $\omega-6$ for normal nervous system function. Alterations in PUFAs signaling are involved in the development of various pathologies of the nervous system, including cancer. It is well established that an omega-6-polyunsaturated fatty acid ( $\omega$-6 PUFA)-rich diet has a pro-tumoral effect, whereas the consumption of an $\omega-3$ rich diet has an anti-tumoral effect. This review aims to offer a better understanding of brain cancer and PUFAs and to discuss the role and impact of PUFAs on the development of different types of brain cancer. Considering the difficulty of antitumor drugs in crossing the blood-brain barrier, the therapeutic role of $\omega-3 / \omega-6$ PUFAs against brain cancer would be a good alternative to consider. We highlight our current understanding of the role of PUFAs and its metabolites (oxylipins) in different brain tumors, proliferation, apoptosis, invasion, angiogenesis, and immunosuppression by focusing on recent research in vitro and in vivo.
\end{abstract}

Keywords: polyunsaturated fatty acids; brain cancer; oxylipins

\section{Overview Brain Cancer}

Primary brain tumors include a heterogeneous group of non-malignant and malignant tumors arising from the brain parenchyma and its related structures. These tumors are considered an important cause of high mortality in adults and children [1]. In 2018, the World Health Organization (WHO) reported over 18,078,957 new cases and 9,555,027 deaths for both men and women [2]. According to the Central Brain Tumor Registry of the United States (CBTRUS) Statistical Report in 
2011-2015, new primary brain tumor diagnoses included 69.1\% benign tumors (271,705 cases) and $30.9 \%$ malignant tumors (121,277 cases) in the USA [3]. The most frequently reported brain cancer was meningioma at $37.1 \%$, pituitary cancer at $16.4 \%$, glioblastoma at $14.7 \%$, and nerve sheath at $8.5 \%$ [3]. The WHO classifies brain tumors according to risk factor, present symptoms, treatments, outcomes, and others $[2,4,5]$. Within brain tumors, meningioma, pituitary tumors, and low-grade astrocytoma are considered benign brain tumors, in which tumor cells rarely invade the normal cells around them. Benign tumor cells have distinct borders and a slow growing speed. In contrast, oligodendroglia and high-grade astrocytoma are malignant brain tumors; they quickly spread within the brain or spinal cord and have indistinct borders and rapid progression rates [5,6]. The symptoms that the patient with brain cancer presents depend on the specific site of the primary tumor in the brain [7]. In a study with malignant glioma, the patients experienced symptoms like headaches, memory loss, cognitive changes, motor deficits, language deficits, seizures, personality changes, visual problems, changes in consciousness, nausea or vomiting, sensory deficits, and papilledema [8,9]. Genetic-associated diseases are one of the risk factors for brain cancer, including Cowden disease, Gorlin syndrome, Li-Fraumeni syndrome, Neurofibromatosis types 1 and 2, Tuberous sclerosis complex, Turcot syndrome, and Von Hippel-Lindau disease. The administration of drugs such as sleeping pills and anti-histaminic drugs is another risk factor causing brain cancer [10]. Other than genetics and drugs, environmental factors like radiation (ionizing and non-ionizing) [10,11] or smoking can also cause brain cancer. Besides this, a previous medical history of epilepsy, head trauma, seizures, age, infectious agents, hormones, allergies, immune-related conditions, chronic inflammation, obesity, and nutritional factors potentially cause brain cancer as well $[4,10,12]$. Additionally, roughly $20-40 \%$ of all other cancers will eventually develop brain metastasis [13]. Moreover, the average survival for patients with brain metastases is typically less than 6 months [14]. In adults, the most frequent primary tumor types that can metastasize to the brain are lung and breast carcinomas and malignant melanoma (up to $75 \%$ of brain metastasis) $[15,16]$. In contrast, the primary tumors most likely to metastasize to the brain in children and teenagers are sarcomas and germ cell tumors [17]. Brain tumor treatments are limited due to the location of the organ. Standard treatments for several types of brain cancer include surgery, radiotherapy, and the administration of chemotherapy drugs [18]. Surgery is often affected by the tumor size and location [19]. Additionally, the administration of radiation is limited by the potential damage to surrounding tissue, which can lead to severe functional disabilities in patients [20,21].

Additionally, antitumor drugs are ineffective in the brain as they cannot cross the blood-brain barrier (BBB). The BBB is a semipermeable barrier that inhibits the diffusion of large molecules and hydrophilic molecules from the bloodstream to the cerebrospinal fluid. Most treatments will not be able to cross the barrier, and those that do require a large dosage to cross the barrier, which can lead to systemic toxicity [22-25]. All these factors make brain cancers the most difficult to treat, making it necessary to develop new therapeutic strategies. Polyunsaturated fatty acid (PUFAs) could be a potential therapeutic alternative because, in addition to being important components of the Central Nervous System (CNS), there are different studies that support the involvement of PUFAs in limiting the development of cancer. The objective of this study is to discuss the compiled evidence using a broad search of the related literature that demonstrates the effect and impact that $\omega-3$ and $\omega-6$ have on the advancement of different types of brain cancer.

\section{Polyunsaturated Fatty Acids (PUFAs)}

There are three types of naturally occurring fatty acids classified by the number of carbon-carbon double bonds present in their fatty acid side chains: saturated, monounsaturated, and polyunsaturated. In particular, PUFAs are fatty acids that contain 14 to 20 or more carbon atoms with several double bonds. PUFAs are important in the composition of the phospholipids of all cell membranes [26]. In 1929, Burr et al. showed that the polyunsaturated linoleic and linolenic fatty acids are essential dietary components $[27,28]$. PUFAs are classified as either $\omega-3$ or $\omega-6$ fatty acids depending on the position of the first unsaturated bond from the terminal methyl group. $\omega-3$ PUFAs include $\alpha$-linolenic acid (ALA) 
(18:3n-3), Eicosapentaenoic acid (EPA) (20:5n-3), and Docosahexaenoic acid (DHA) (22:6n-3), while $\omega-6$ PUFAs include mostly linoleic acid (LA) (18:2n-6), $\gamma$-linolenic acid (GLA) (18:2n-6), and araquidonic acid (ARA) (20:4n-6). LA is the most abundant polyunsaturated fatty acid in nature, and it can be found mainly in seed oils, including soybean, sunflower, safflower, and in wheat germ, grape, hemp, corn, and cotton. ALA is found at high levels in leafy green vegetables, flaxseeds, walnuts, canola oil, and microalgae oil [29-31]. LA can be indirectly converted to ARA in the body and is the main PUFA in the Western diet, comprising more than $85 \%$ of the PUFA intake [32]. ALA is converted in vivo to EPA and DHA [33]. EPA and DHA are found in seafood, and in particular salmon, tuna, sardine, mackerel, and krill oils [34].

PUFAs, by oxidative reactions, produce oxylipins; these oxylipins are essential metabolites in our body. Three pathways can form the oxylipins: (1) the cyclooxygenase pathway (COX), (2) the lipoxygenase pathway (LOX), and (3) the cytochrome P450 pathway (CYP450). The metabolism of ARA through the COX pathway generates 2-series prostaglandins $\left(\mathrm{PGE}_{2}\right)$ and thromboxanes $\left(\mathrm{TXA}_{2}\right)$ [35]. Meanwhile, ARA metabolism through the LOX pathways generates hydroperoxyl-eicosatetraenoic acids (HpETE), which are quickly converted to hydroxy-eicosatetraenoic fatty acids (5- 12- and 15-HETE) employing glutathione peroxidase. The 4-series leukotrienes $\left(\mathrm{LTB}_{4}, \mathrm{LTC}_{4}, \mathrm{LTD}_{4}\right)$ are generated at the same time [36]. Additionally, 4-series leukotrienes (Leuk 4) can also be generated from 5-HpETE by the LOX pathway [37]. The third pathway involves cytochrome 450 enzymes, which may have $\omega$-hydroxylase or epoxygenase activity. The metabolism of ARA by $\omega$-hydroxylase results in the formation of 19- and 20-HETE, while the activity of the epoxygenase leads to four epoxy-eicosatrienoic cis-acids (EETs), which can be converted to dihydroxy eicosatetraenoic acids (DiHETs) by the enzyme epoxy-hydroxylase (sEH). EETs have various biological activities, while DHET metabolites are considered to be biologically inactive [38]. Besides, EPA is the precursor of the 3-series prostaglandins $\left(\mathrm{PGE}_{3}, \mathrm{PGF}_{3}\right)$, thromboxanes $\left(\mathrm{TXA}_{3}\right)$, resolvins, protectins, and maresins through the COX pathway. Meanwhile, the LOX pathway produces the 5-series leukotrienes $\left(\mathrm{LTB}_{5}, \mathrm{LTC}_{5}, \mathrm{LTD}_{5}\right)$. The CYP450 pathway, through $\omega$-hydroxylase, generates HEPEs, and epoxygenase activity generates EpETEs (Epoxyeicosatetraenoic acids), which can be converted to Dihydroxy eicosatetraenoic acids (DiHETEs) again through this pathway [39] (Figure 1).

The right amount of dietary PUFAs are generally considered to have beneficial health effects. However, $w-3$ and $w-6$ PUFAs have opposing effects on metabolic functions in our bodies. Eicosanoid derivatives from ARA ( $\omega-6$ PUFAs) are generally pro-inflammatory and are involved in various pathological processes such as atherosclerosis, bronchial asthma, and inflammatory bowel disease [40]. Eicosanoids derivatives from EPA ( $\omega-3$ PUFAs) are predominantly anti-inflammatory; can inhibit platelet aggregation; and are therapeutic in some clinical conditions, such as collagen vascular diseases, hypertension, diabetes mellitus, metabolic syndrome, psoriasis, eczema, atopic dermatitis, coronary heart disease (CHD), atherosclerosis, and cancer [39]. Thus, a balanced ratio of $\omega-3$ and $\omega-6$ PUFAs in the diet is necessary for health.

A recent meta-analysis indicated that processed meat consumption was associated with a higher risk of brain tumors [41], while intakes of vegetables and fruits [42] can reduce the risk. In addition, it has been shown that fish rich in $\omega-3$ polyunsaturated fatty acids have been found to be associated with a lower risk of several types of cancer and are beneficial for brain development. Wei et al. found in a meta-analysis that fish intake might be associated with a lower risk of brain cancer [43]. In contrast, a diet rich in $\omega-6$ polyunsaturated fatty acids can be associated with a high risk of brain cancer [44].

The recommended dietary ratio of $\omega-6 / \omega-3$ PUFAs for health benefits is 1:1-2:1. However, the current Western population has a high consumption of $\omega-6$ PUFAs (the foods rich in $\omega-6$ PUFAs are seed oils, including soybean, sunflower, safflower; wheat germ; grape; hemp; corn; and cotton) [29,30], with the ratio of $\omega-6 / \omega-3$ PUFAs at 15:1 to 16.7:1 [45]. Global statistics that quantify the global consumption of key dietary fats and oils by country, age, and sex from 1990 to 2010 reveal that in 2010, the global mean intake of seafood $\omega-3$ fats was $163 \mathrm{mg} / \mathrm{day}$, with significant regional variation (50 to $700 \mathrm{mg} /$ day) and national variation (5 to $3886 \mathrm{mg} /$ day). The highest intakes were observed in 
Iceland (1189 mg/day), Barbados (1178 mg/day), Japan (995 mg/day), the Maldives, the Seychelles, Denmark, Malaysia, South Korea, and Thailand [46]. In another global study from 1980 to 2016, Stark et al. reported that regions with high EPA (and DHA blood levels $(>8 \%)$ ) included East Asia, Scandinavia, and areas with indigenous populations or populations not fully adapted to Westernized food habits. Very low blood levels of EPA $(<4 \%)$ were observed in North America, Central and South America, Europe, the Middle East, Southeast Asia, and Africa [47]. In the United States, the estimated per capita consumption of soybean oil (the main source of LA, $\omega-6$ PUFA) increased 1000-fold from 1909 to 1999 . The availability of LA increased from $2.79 \%$ to $7.21 \%$, whereas the availability of ALA ( $\omega-3$ PUFA) increased from $0.39 \%$ to $0.72 \%$. Similarly, the ratio of LA to ALA increased from 6.4 to 10.0 in the same century [48]. These studies suggest a low level of $\omega-3$ PUFA consumption in most of the world; the unbalance of $\omega-3 / \omega-6$ diets could potentially lead to health issues.

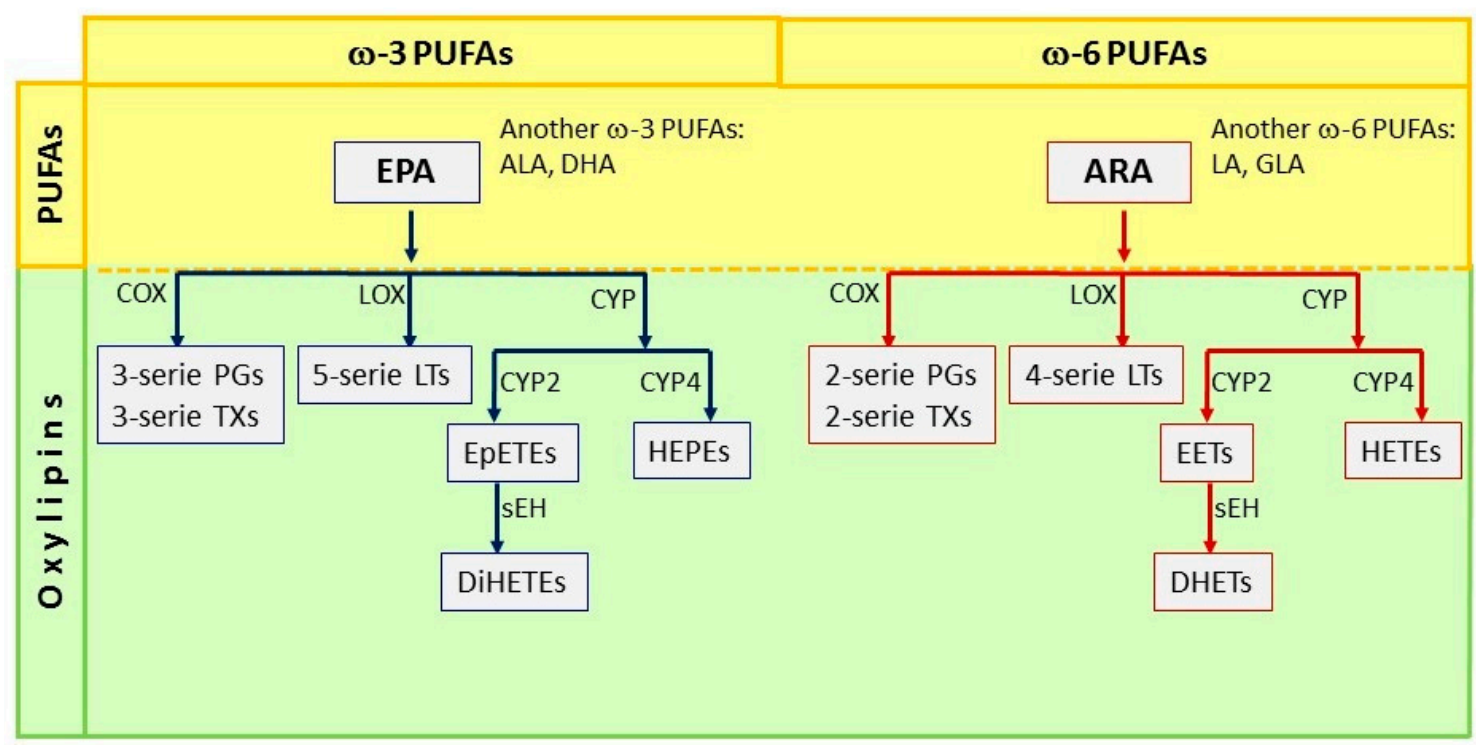

Figure 1. Pathways of synthesis of oxylipins from Eicosapentaenoic acid (EPA) and ARA PUFAs. $\omega-3$ polyunsaturated fatty acids (PUFAs) include $\alpha$-linolenic acid (ALA), Eicosapentaenoic acid (EPA), and Docosahexaenoic acid (DHA); the metabolism of EPA by Cyclooxygenase (COX) leads to the formation of 3-series prostaglandins (PGs) and 3-series Thromboxanes (TXs); the Lipoxygenase (LOX) pathway generates 5-series Leukotrienes (LTs); and the cytochrome P450 (CYP2) epoxygenases leads to the formation of Epoxyeicosatetraenoic acids (EpETEs). EpETEs are further metabolized by soluble epoxide hydrolase (sEH) to form the fatty acid diols termed Dihydroxy eicosatetraenoic acids (DiHETEs); CYP4 generates hydroxyeicosapentaenoic acids (HEPEs). In contrast, $\omega-6$ PUFAs include linoleic acid (LA), $\gamma$-linolenic acid (GLA), and araquidonic acid (ARA). The metabolism of ARA through the COX pathway generates 2-series prostaglandins (PGs) and thromboxanes (TXs), while through the LOX pathway it generates the 4-series leukotrienes; $\omega$-hydroxylase results in the formation of hydroxyeicosatetraenoic acids (HETEs); the activity of the epoxygenase leads to epoxy-eicosatrienoic acids (EETs), which can be converted to dihydroxy eicosatetraenoic acids (DiHETs) by the enzyme epoxy-hydroxylase (sEH).

\section{Importance of PUFAs in Brain Functioning and Brain Cancer}

PUFAs and oxylipins are necessary for normal physiological events in the nervous system, and they are highly prevalent in the synapses and retina [49]. ARA and DHA are the major PUFAs in the rat brain, comprising $81-90 \%$ and $6-12 \%$, respectively [50]. The brain has two main sources of DHA plasma pools: the nonesterified pool and the lysophosphatidylcholine (LPC) pool. The plasma non esterified-DHA (NE-DHA) is the main contributor to brain DHA [51,52]. Significantly, LA and EPA are highly represented in the cerebellum, while ARA and DHA are in the cerebrum [53]. $\omega-3$ PUFAs play a fundamental role in maintaining the membrane integrity and fluidity, which is 
crucial for neurotransmitter binding, and signaling [54]. In vivo studies indicate that dietary PUFA supplementation can alter the PUFA composition in both normal brain tissue [55] and intracerebrally implanted tumor tissue [56]. In addition, several studies showed that the gut microbiota composition affects the gut-brain axis and has been associated with different behavioral, mood, and psychological disorders (depression, anxiety, and autism). Importantly, $\omega-3$ PUFAs restore the bacterium phylum Firmicutes/Bacteroidetes ratio and increase the taxa Lachnospiraceae that leads to the high production of anti-inflammatory compounds like butyrate [57]. The $\omega-3 / \omega-6$ ratio is therefore important in maintaining an appropriate level of biological membrane fluidity, which is in turn essential for the ion channel function, membrane receptor activity, and release of neurohormones [58].

Remarkably, PUFAs have the advantage of being able to cross the BBB by a non-fenestrated layer of cerebral microvascular endothelial cells (BMEC) through two ways [59]: (1) membrane-localized fatty acid transport proteins (FATP1 [60], FATP4 [51], fatty acid translocase (FAT)/CD36 [51], and Mfsd2a [61]) and (2) cytosolic localized fatty acid-binding proteins (FABP3 [62], FABP4 [62], and FABP5 [23,51,62,63]); this ligand-receptor union facilitates the brain fatty acid uptake and trafficking [64]. FATP1 [60] and FABP5 [63] are key players that regulate the brain uptake of NE-DHA [52]; Mfsd2a is the major contributor of LPC-DHA [61]. The FATP-4, CD36, and FABP5 receptors promote the permeability of the LA [51]; whether these receptors facilitate DHA transport across the BBB has not been investigated [63]. Furthermore, FABP3, FABP5, and FABP7 are localized in neurons, glial cells, and other brain parenchymal cells [65] and facilitate the brain uptake of ARA, DHA, and EPA [66,67]; saturated fatty acids [67,68]; and DHA [67,69], respectively. Additionally, the BBB contains EP1 and $\mathrm{EP} 2$ receptors that, through the union $\mathrm{PGE}_{2}$, increase the $\mathrm{BBB}$ permeability via an increase in the tyrosine phosphorylation of occluding $[70,71]$. Other proposed models involve the delivery of PUFAs by lipoproteins in esterified form, in which low-density lipoprotein receptors bind to lipoproteins. Lipoprotein lipases on the surface of the cerebral endothelial cells detach PUFAs by the hydrolysis of ester bonds [72]. Finally, PUFAs can cross the BBB by passive diffusion through a flip-flop mechanism. These mechanisms depend on local fluctuations in ion densities that form strong local electrical fields across the membrane bilayer, which forms water pores. Ion leakage will reduce the strength of the local field, but the pore will be able to remain open for a long time [52,72,73]. In Figure 2, we present the combination of the three proposed models that explain how PUFAs cross the BBB.

The BBB is a semipermeable barrier that inhibits the diffusion of large molecules and hydrophilic molecules from the bloodstream to the cerebrospinal fluid. Most treatments will not be able to cross the barrier and those that do require a large dosage to cross the barrier, which can lead to systemic toxicity. Regarding drugs that can cross the BBB, most must cross by transmembrane diffusion, which favors high lipid solubility. However, after crossing the barrier the molecule must then travel through the liquid setting of the colony stimulating factor (CSF). A higher lipid solubility of the drug will cause lower amounts of the drug to get into the brain. Other methods of crossing are those of L-DOPA and caffeine, which use saturable transport systems [74].

Interestingly, a recent study shows that FABP5 can uptake fatty acids but not drugs like diazepam, pioglitazone, and troglitazone [23], which can cause treatment failure in neurological diseases.

In another hand, alterations in PUFA signaling are involved in the development of several diseases of the nervous system. Epidemiological studies suggest that systemic inflammation increases the risk of developing neurodegenerative conditions, including depression, schizophrenia, Alzheimer's, and Parkinson's disease, as well as cancer. Inflammatory processes derived from $\omega-6$ PUFAs consumption induces increased cerebral oxidative damage and secondary neurotoxicity [75]; this could promote chronic neurodegeneration and neuroinflammation, which is a step in the potential development of cancer. Additionally, several reports associate the overexpression of enzymes such as Ciclooxigenase-2 (COX-2), prostaglandin E synthase (PGES), and Cytochrome P450 Family 2 and 4 (CYP2s and CYP4s) with the development of different types of brain cancer. The overexpression of these enzymes is proposed as a major factor in promoting tumor development, which is linked to increased aggressiveness and poor prognosis [76-78]. In particular, high-grade malignant gliomas with 
high mitotic levels present higher COX-2 expression than low-grade gliomas with less proliferative indexes. The higher tumoral expression of COX-2 is strongly correlated with poor and clinically more aggressive gliomas [79]. Below, we presented some examples of different studies on PUFAs and the effect of oxylipins on different processes that participate in the development of different types of brain cancer.

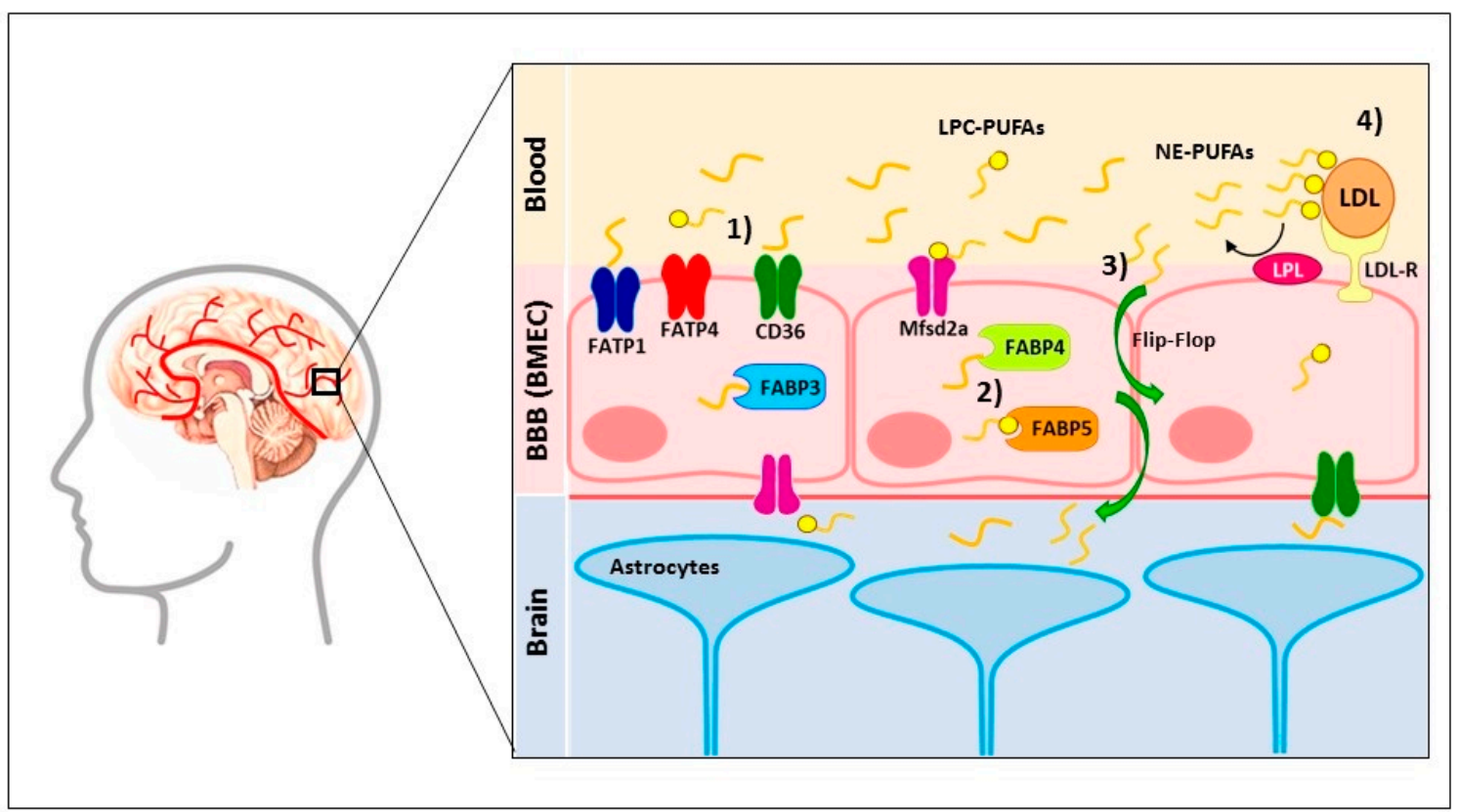

Figure 2. Mechanisms that polyunsaturated fatty acids (PUFAs) cross the blood-brain barrier (BBB). PUFAs have the advantage of being able to cross the BBB by the non-fenestrated layer of cerebral microvascular endothelial cells (BMEC). Four ways are proposed: (1) membrane-localized fatty acid transport proteins (FATP1, FATP4, fatty acid translocase (FAT)/CD36, and Mfsd2a). (2) Cytosolic-localized fatty acid binding proteins (FABP3, FABP4, and FABP5); this ligand-receptor union facilitates the brain fatty acid uptake and trafficking. FATP1 and FABP5 are key players that regulate the brain uptake of NE-DHA. Mfsd2a is the major contributor of LPC-DHA; the FATP-4, CD36, and FABP5 receptors promote the permeability of the LA. (3) PUFAs can cross the BBB by passive diffusion through a flip-flop mechanism. (4) Low-density lipoproteins (LDL) bind to the low-density lipoprotein receptor (LDL-R), and then lipoprotein lipases (LPL) liberate PUFAs by the hydrolysis of ester bonds. LPC-PUFAs_-Lysophosphatidylcholine-Polyunsaturated fatty acids, NE-PUFAs-Non-Esterified-Polyunsaturated fatty acids.

\subsection{The Implication of PUFAs on Inflammation in Brain Cancer}

Inflammation characterizes the course of acute and chronic diseases and is largely responsible for metabolic and behavioral changes in patients. Several studies indicate that during cancer, functional modifications take place, including an increased concentration of pro-inflammatory cytokines, which induce neuro-inflammation and promote tumor growth. PUFAs play a central part in modulating the inflammatory process in the development of brain cancer. It has been shown that the oxylipins derived from $\omega-3$ PUFAs, such as $\mathrm{LXA}_{4}$, inhibit inflammatory pain processing through the inhibition of extracellular-regulated kinase (ERK) and c-Jun N-terminal kinase (JNK)-activated pathways in spinal astrocytes [80], and resolvin D1 inhibits the pro-inflammatory cytokine IL- $1 \beta$ expression in microglial cells [81]. In addition, the DHA derivate, 17S-hydroxy-containing docosanoids (17RS-HpDHA), and $17 S$ series resolvins regulate both leukocytes to reduce infiltration in vivo and in glial cells by blocking their pro-inflammatory cytokine production [82]. 
In contrast, some studies suggest that the $\omega-6$ PUFAs facilitate proinflammatory processes in brain cancer. Ferreira et al. evaluated tumor samples and showed that grade IV glioblastoma patients present high quantities of ARA and the pro-inflammatory prostanoids $\mathrm{TXB}_{2}, \mathrm{PGD}_{2}, \mathrm{PGE}_{2}$, and $\mathrm{PGF}_{2 \alpha}$ versus patients with grade II/III tumors. Interestingly, the patients with high levels of pro-inflammatory prostanoids had significantly decreased survival rates [83]. Importantly, $\mathrm{PGE}_{2}$ in glioblastoma cells increases the overexpression of immunosuppressive cytokines, such as interleukin 6 (IL-6), interleukin 10 (IL-10), and granulocyte-macrophage colony-stimulating factor (GM-CSF). Therefore, this process blocks $\mathrm{T}$ cell infiltration and proliferation and the subsequent suppression of the recruitment and proliferation of naive effector immune cells [84]. All this evidence shows us that PUFAs play a fundamental role in the regulation of inflammatory mediators that are known to affect the development of brain cancer.

\subsection{Regulation of Proliferation in Brain Cancer Cells by PUFAs}

One of the main characteristics of tumor cells is uncontrolled proliferation [85]. Several studies have shown the involvement of PUFAs in modulating this process in brain cancer progression. For example, ARA and DHA have been shown to modulate cell proliferation, differentiation, and migration through PKC activities in a fatty acid-binding protein (B-FABP)-dependent manner in glioblastoma multiforme cells (U87) [86]. Besides this and contrary to what has been reported, Leaver et al. showed that $\gamma$-linolenic acid (GLA) decreased proliferation both in vitro (C6 glioma cell line and multicellular glioma spheroids prepared from cell lines) and in vivo (implanted C6 glioma cells in rats) models through MTT assay and proliferating cell nuclear antigen (PCNA) and Ki-67 stain, respectively [87].

The oxylipins derived from $\omega-6$ PUFAs play an important role in the promotion of the proliferation of brain cancer cells. Several studies highlight the participation of $\mathrm{PGE}_{2}$, which stimulates cell proliferation through binding its receptor prostaglandin E receptor subtype EP1 in the KMG4 glioma cell line [88]. PGE 2 enhanced cell survival and proliferation through its ability to trans-activate the EGFR and to activate the $\beta$-catenin in an in vitro model with glioblastoma primary cultures [89]. It induces Id1 via the EP4-dependent activation of mitogen-activated protein kinase (MAPK) signaling, and the Egr1 transcription factor is important for the tumor cell self-renewal and radiation resistance [90]. Additionally, the exogenous administration of $\mathrm{PGE}_{2}$ also induced significant increases in cell proliferation in T98G human glioma cells [91]. Additionally, Payner et al. reported that microsomal prostaglandin E synthase-1 (mPGES-1) plays a critical role in promoting astroglioma cell growth via the $\mathrm{PGE}_{2}$-dependent activation of type II PKA (Protein kinase A) in the human astroglioma cell line U87-MG [76]. Furthermore, Ferreira et al. reported that the increase in $\mathrm{PGD}_{2}$ production in glioblastoma (GBM) patients correlates with an increase in the growth and invasion of glioma [83]. On the other hand, leukotrienes such as $\mathrm{LTB}_{4}$ and $\mathrm{LXA}_{4}$ regulate growth-related gene expressions, such as EGFR, cyclin E, p27, and caspase-8 in neuronal stem cells (NSCs) [92]. The exogenous administration of 20-HETE increases the growth of human glioma cells (U251) in vitro; transfected U251 cells with CYP4A1 complementary deoxyribonucleic acid (cDNA) increases its proliferation, and the implantation of these transfected cells in the brain of rats resulted in larger tumors compared with the controls [78].

These studies provide evidence that PUFAs affect the proliferative activities of tumors and may indicate potential brain tumor behavior. The evidence also strongly suggests that the inhibition of $\omega-6$ PUFAs could have the potential to be a regulating strategy in tumor progression.

\subsection{The Effect of PUFAs on Apoptosis in Brain Cancer}

Apoptosis is a well-conserved and highly regulated mechanism of cell death for the removal of unnecessary, surplus, aged, or damaged cells. The dysregulation of apoptosis can result in the persistence of mutated cells, leading to malformations; autoimmune diseases; neurodegenerative diseases; and cancer, including brain cancer. Recently, PUFAs have been identified as important mediators for apoptosis modulation in brain tumors. 
Treatment with $\omega-3$ PUFAs, such as EPA, together with radiation increased apoptosis through the production of reactive oxygen species (ROS) in human C6 glioma cells [87]. The DHA-induced poly (ADP-ribose) polymerase (PARP) cleavage increased the population of sub-G1 cells and increased the number of terminal deoxynucleotidyl transferase dUTP nick end labeling (TUNEL)-positive cells, which are indicators of apoptosis, and caused an increase in autophagic activity in glioblastoma cells [93]. Additionally, EPA and DHA supplementation plus irradiation in rat astrocytoma cells (36B10) caused alterations in the fatty acid profile and enhanced radiation-induced cytotoxicity [94], which is mediated through the generation of free radicals and lipid peroxidation [95].

Unlike the evidence in other cancers, where $\omega-6$ type PUFAs inhibit apoptosis [96], interestingly the reports on brain cancer indicate a contrary effect. For example, Bell et al. showed that GLA induces apoptosis in glioma spheroids derived from U87, U373, MOG-G-CCM, and C6 cell lines, which was evaluated through morphological and terminal deoxynucleotidyl transferase dUTP nick end labeling (TUNEL) assays [97]. Additionally, Leaver et al. demonstrated that the intra-tumoral administration of ARA and GLA using osmotic minipumps in an in vivo C6 glioma model augmented apoptosis levels. The apoptotic process was evaluated through morphological cell changes, the presence of phosphatidylserine cell surface, mitochondrial permeability, and TUNEL assay [87]. GLA-treated tumors have increased free radicals and lipid peroxides and a decreased antioxidant content, a decreased expression of oncogenes ras and B-cell lymphoma 2 (Bcl-2), and an enhanced activity of p53 [39]. Additionally, Lalier et al. has shown that the intracellular injection of $\mathrm{PGE}_{2}$ induced dose-dependent apoptosis in glioblastoma cells, which was dependent on the presence of pro-apoptotic protein, Bcl-2-associated X protein (Bax) [98]. There is accumulating evidence on the role of neuronal apoptosis in diseases of the nervous system. Researchers are now looking forward to the exciting prospect of developing effective therapeutic strategies based on the manipulation of this physiological process.

\subsection{Induction of Angiogenesis and Metastasis by PUFAs and Its Implication in Brain Cancer Progression}

Numerous studies have demonstrated that angiogenesis is up-regulated in cancer development and is necessary for tumor growth and metastasis in almost all types of cancers, including brain cancer $[99,100]$. Both PUFAs and the enzymes that participate in their metabolism have been shown in different studies to regulate angiogenic factors in brain cancer. For example, Wang et al. showed that the addition of DHA and etoposide resulted in the marked suppression of the expression of the FGF-2 and EGFR genes involved in angiogenesis in medulloblastoma cell lines (Daoy and D283) [101]. On the other hand, Xu et al. proposed that EGF EGFR binding led to the p38-MAPK activation pathway. This pathway induces Sp1/Sp3 transcription factors, and it seems necessary for the EGFR-dependent transactivation of the COX-2 promoter, increasing $\mathrm{PGE}_{2}$ production. In addition, they showed that the in vitro treatment of LN229/puro and SF767 glioma cells with PGE 2 increased the vascular endothelial growth factor (VEGF) messenger ribonucleic acid (mRNA) expression. This pathway may contribute to the neovascularization of malignant gliomas [102]. Guo et al. demonstrated that the U251 human glioblastoma cancer cell line transfected with CYP4A1 cDNA (U251 O) increased the formation of 20-HETE, and this correlates with the high VEGF and pERK1/2 expression compared with the control U251 cells, which suggests that 20-HETE may have pro-angiogenic properties in U251 human gliomas [78]. Further, Chen et al. reported that the inhibition of 20-HETE with $N$-hydroxy- $N^{\prime}$-(4-butyl-2-methylphenol) formamidine (HET0016) in an in vivo model (growth U251 human glioblastoma cancer cells in the rat cornea) reduces corneal neovascularization by $70 \%$ compared with a control vehicle. The author attributed this effect to the decreased VEGF, FGF-2 and EGF levels [103]. Additionally, the CYP2C11 enzyme in rat astrocytes and CYP4X1 in the rat brain formed EETs, which promoted blood vessel formation, angiogenesis, and vasodilation in the rat brain $[77,104]$. Moreover, Zhang et al. reported that all region isoforms (5,6-EET, 8,9-EET, 11,12-EET and 14,15-EET) EETs induce angiogenesis. However, 8,9-EET and 11,12-EET had a more potent activity. The authors suggest that the mechanism by which EETs induce endothelial mitogenic activity appears to involve the antagonism of the tyrosine kinase pathway [105]. The inhibition of EETs in brain tissue with 17-octadecenoic acid (17-ODYA) and miconazole significantly 
reduced the tumor capillary formation and glial tumor size and resulted in an increased animal survival time in an intracranial tumor rat model with RG2 cells [106].

Metastases can cause severe outcomes for CNS, and poor prognosis often leads to high mortality. However, the lack of statistics often leads to an underestimation of the incidence of even symptomatic brain metastases. Several studies showed the important role of PUFAs in the development of brain metastasis. Interestingly, DHA binds to and sequesters FABP7 (Fatty acid-binding protein 7) to the nucleus, resulting in a decreased cell migration in U87 MG cells [107]. A recent study by Zou et al. showed that astrocytes have a high content of PUFAs (mainly ARA, mead acid, and DHA) that act as "donors" of PPAR $\gamma$ in the invading cancer cells. In addition, the authors directly added AA into the culture medium and promoted the growth of brain metastatic cancer cells through the PPAR $\gamma$ pathway, enhancing cell proliferation and metastatic outgrowth in the brain [108]. In addition, DHA and EPA decreased the COX-2 mRNA expression and $\mathrm{PGE}_{2}$ production; it caused a decrease in migration in a matrigel invasion assay in the human melanoma cell line (70W) that metastasizes to the brain in mice. Additionally, the exposure to $\mathrm{PGE}_{3}$ significantly decreased invasion in an in vitro assay with $70 \mathrm{~W}$ cells, a human melanoma cell line that metastasizes to the brain in nude mice [109].

Concerningly, ARA and tumor necrosis alpha (TNF- $\alpha$ )-modulated COX-2 expression in 70W cells generate an increase in the production of $\mathrm{PGE}_{2}$ and upregulate in vitro invasion [109]. The presence of $\mathrm{PGE}_{2}$ increased brain invasion and migration through several mechanisms. For example, Chiu et al. reported that 12-O-tetradecanoylphorbol-13-acetate (TPA) stimulation, through the activation of protein kinase $\mathrm{C}$ (PKC) and ERKs, increased the COX-2 gene expression; elevated PGE 2 production; and promoted matrix metalloproteinase-9 (MMP-9) activation, which induced in vitro migration/invasion in U87 glioblastoma cells [110]. Another study by Wang et al. demonstrated that the nuclear factor of activated T cells 1 (NFATC1) promoted the induction of COX-2 and PGE2, causing glioblastoma U251 cell invasion [111]. Additionally, Wang showed that $\mathrm{PGE}_{2}$ increased the migration of human glioblastoma cell lines in vitro through the prostaglandin receptors, EP2 or EP4 [112]. Additionally, Gomes et al. reported that the addition of exogenous $\mathrm{PGE}_{1}$ and $\mathrm{PGE}_{2}$ in T98G human glioma cells causes an increase in cell migration compared with controls through a transwell migration assay [91].

The pathophysiology of brain metastases is a complex-multistage process mediated by molecular mechanisms. From the primary organ, cancer cells must transform, grow, and be transported to the CNS where they can lay dormant for a long time before invading and growing. Understanding the pathophysiology of brain metastasis is necessary, because it may lead to the development of more efficient therapies to combat brain tumor growth or to possibly making the CNS an undesirable environment for tumor progression. Treatment by PUFAs is a possible option to combat brain cancer with the advantage that PUFAs can easily cross the BBB. Figure 3 shows the participation of PUFAs and oxylipins in the development of brain cancer; $\omega-3$ PUFAs have an anti-tumoral activity, while $\omega-6$ PUFAs have a pro-tumoral activity. 


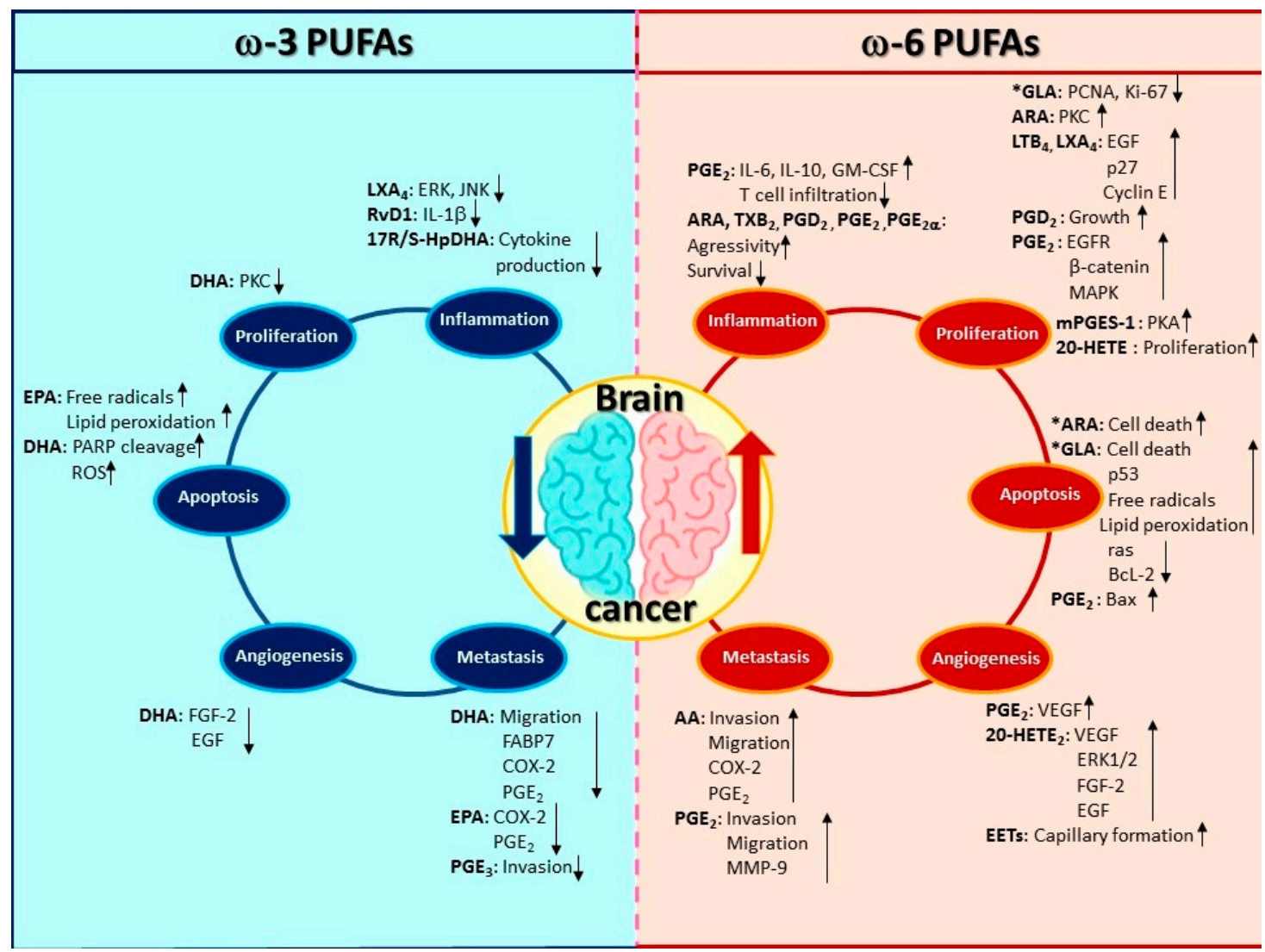

Figure 3. PUFAs and oxylipins involved in brain cancer development. PUFAs play a central part in modulating the different mechanisms involved in the development of brain cancer. In general, the evidence shows that $\omega-3$ PUFAs have antitumor effects, whereas $\omega-6$ PUFAs are attributed a pro-tumor tumor effect. However, interestingly GLA has antiproliferative effects and ARA and GLA show proapoptotic effects. Polyunsaturated fatty acids (PUFAs), Eicosapentaenoic acid (EPA), $\alpha$-linolenic acid (ALA), Docosahexaenoic acid (DHA), Arachidonic acid (ARA), Linoleic acid (LA), $\gamma$-linolenic acid (GLA), Resolvin D1 (RvD1), 17S-hydroxy-containing docosanoids (17RS-HpDHA), Hydroxy-eicosapentaenoic acids (HEPEs), epoxy-eicosatrienoic cis-acids (EETs), 20-Hydroxy-eicosatetraenoic acids (20-HETE), Interferon-gamma (IFN- $\gamma$ ), Interleukin 6 (IL-6), Interleukin 10 (IL-10), granulocyte-macrophage colony-stimulating factor (GM-CSF), protein kinase $C$ $(\mathrm{PKC})$, Mitogen-Activated Protein Kinases (MAPK), Prostaglandin $\mathrm{D}_{2}\left(\mathrm{PGD}_{2}\right)$, Prostaglandin $\mathrm{E}_{1}\left(\mathrm{PGE}_{1}\right)$, Prostaglandin $\mathrm{E}_{2}\left(\mathrm{PGE}_{2}\right)$, Prostaglandin $\mathrm{E}_{2 \alpha}\left(\mathrm{PGE}_{2 \alpha}\right)$, Prostaglandin $\mathrm{E}_{3}\left(\mathrm{PGE}_{3}\right)$, Leukotriene $\mathrm{B}_{4}\left(\mathrm{LTB}_{4}\right)$, Lipoxin $\mathrm{A}_{4}\left(\mathrm{LXA}_{4}\right)$, poly (ADP-ribose) polymerase (PARP), Vascular Endothelial Growth Factor (VEGF), fatty acid-binding protein 7 (FABP7), extracellular signal-regulated kinase (ERKs), Epidermal growth factor receptor (EGFR), and Matrix metalloproteinase-9 (MMP-9).

\section{Concluding Remarks and Future Perspectives}

Brain cancer represents one of the most aggressive types of cancer, with a poor prognosis and a high mortality rate. The evidence that we present demonstrates that the consumption of PUFAs, particularly $\omega-3$ PUFAs, may be a potential therapeutic alternative since they are differentially expressed in different parts of the brain and constitute a fundamental part in the development and neurological functioning of the CNS. In contrast, the consumption of w-6 PUFAs are implicated in the development of brain cancer. Interestingly, PUFAs can easily cross the BBB, unlike some chemotherapeutic drugs.

Several studies in different types of brain cancer, primarily glioma, have shown that the presence of $\omega$-3 PUFAs/oxylipins downregulates tumor growth, proliferation, angiogenesis, and metastasis. Meanwhile, $\omega-6$ PUFAs/oxylipins induce an increase in these pro-tumor processes. These data are relevant, considering that the human population is exposed to a higher proportion of $\omega-6$ than $\omega-3$ 
PUFAs in their diet. Another important aspect is that several of the enzymes involved in the metabolism of PUFAs, such as COX-2, CYP2J2, CYP4A11, and sEH, are involved in the accumulation of PUFAs that result in the increase in tumors, because there are highly expressed in various types of brain cancer; therefore, it is important to consider the use of inhibitors of these enzymes as an alternative treatment. Considering this, oxylipins and PUFAs are difficult to measure.

Author Contributions: M.M.-A. contributed to the abstract, background information, conclusion, and all the figures. B.T.-R. contributed to the background information. Z.T. contributed to writing the background information. S.A. contributed to the background information and manuscript writing. M.M.-M. contributed to writing the background information. O.M.V. contributed to the background information about BBB and manuscript editing. J.P.-C. contributed to the abstract, background information, conclusion, and manuscript writing. S.H.-Y. contributed to the abstract, background information, conclusion, and the coordination and writing of the manuscript. All authors have read and agreed to the published version of the manuscript.

Funding: The Mexico Federal Funds [Grant HIM/2017/014, S.H.-Y.] and NIEHS [Grant R01 ESO24434], NIEHS/Superfund Research Program [P42 ES004699] funded this study.

Conflicts of Interest: The authors declare that they have no conflict of interest.

\section{Abbreviations}

\begin{tabular}{|c|c|}
\hline ALA & $\alpha$-linolenic acid \\
\hline ARA & Arachidonic acid \\
\hline Bax & Bcl-2-associated X protein \\
\hline BBB & Blood-Brain-Barrier \\
\hline$B c l-2$ & B-cell lymphoma 2 \\
\hline B-FABP & Fatty acid-binding protein \\
\hline BMEC & Cerebral microvascular endothelial cells \\
\hline CBTRUS & Central Brain Tumor Registry of the United States \\
\hline CD36 & Fatty acid translocase \\
\hline $\mathrm{CHD}$ & Coronary heart disease \\
\hline CNS & Central nervous system \\
\hline $\mathrm{COX}$ & Cyclooxygenase \\
\hline COX-2 & Cyclooxygenase 2 \\
\hline CYP450 & Cytochrome P450 \\
\hline CYP2s & Cytochrome P450 Family 2 \\
\hline CYP2C11 & Cytochrome P450 Family 2 subfamily C member 11 \\
\hline CYP4s & Cytochrome P450 Family 4 \\
\hline CYP4A1 & Cytochrome P450 Family 4 subfamily A member 1 \\
\hline CYP4X1 & Cytochrome P450 Family 4 subfamily X member 1 \\
\hline DHA & Docosahexaenoic acid \\
\hline DiHETES & Dihydroxy eicosatetraenoic acids \\
\hline EGF & Epidermal growth factor \\
\hline EGFR & Epidermal growth factor receptor \\
\hline EPA & Eicosapentaenoic acid \\
\hline 16,17-EpDPE & 16,17-Epoxy docosapentaenoic acid \\
\hline EpETEs & Epoxyeicosatetraenoic acids \\
\hline EETs & Epoxy-eicosatrienoic cis-acids \\
\hline 5,6-EET & 5,6-Epoxy-eicosatrienoic acid \\
\hline 8,9-EET & 8,9-Epoxy-eicosatrienoic acid \\
\hline 11,12-EET & 11,12-Epoxy-eicosatrienoic acid \\
\hline 14,15-EET & 14,15-Epoxy-eicosatrienoic acid \\
\hline EP1 & Prostaglandin E2 receptor 1 \\
\hline EP2 & Prostaglandin E2 receptor 2 \\
\hline EP4 & Prostaglandin E4 receptor 4 \\
\hline EPHX2 & Epoxy-hydroxylase \\
\hline ERK & Extracellular regulated kinase \\
\hline
\end{tabular}




\begin{tabular}{|c|c|}
\hline FABP3 & Fatty acid-binding protein 3 \\
\hline FABP4 & Fatty acid-binding protein 4 \\
\hline FABP5 & Fatty acid-binding protein 5 \\
\hline FABP7 & Fatty acid-binding protein 7 \\
\hline FAT & Fatty acid translocase \\
\hline FATP1 & Fatty acid transport protein 1 \\
\hline FATP4 & Fatty acid transport protein 4 \\
\hline FGF-2 & Fibroblast Growth Factor 2 \\
\hline GBM & Glioblastoma \\
\hline GLA & $\gamma$-linolenic acid \\
\hline GM-CSF & Granulocyte-macrophage colony-stimulating factor \\
\hline HET0016 & $N$-hydroxy- $N^{\prime}$-(4-butyl-2-methylphenol) formamidine \\
\hline HETEs & Hydroxy-eicosatetraenoic acids \\
\hline 5-HETE & 5-Hydroxy-eicosatetraenoic acid \\
\hline 12-HETE & 12-Hydroxy-eicosatetraenoic acid \\
\hline 15-HETE & 15-Hydroxy-eicosatetraenoic acid \\
\hline 19-HETE & 19-Hydroxy-eicosatetraenoic acid \\
\hline 20-HETE & 20-Hydroxy-eicosatetraenoic acid \\
\hline HEPEs & Hydroxy-eicosapentaenoic acids \\
\hline HpETE & Hydroperoxyl-eicosatetraenoic acids \\
\hline 5-HрETE & 5-Hydroperoxyl-eicosatetraenoic acid \\
\hline IL-1 & Interleukin 1 beta \\
\hline IL-6 & Interleukin 6 \\
\hline IL-10 & Interleukin 10 \\
\hline JNK & c-Jun N-terminal kinase \\
\hline LA & Linoleic acid \\
\hline LDL & Low density lipoprotein \\
\hline LDL-R & Low density lipoprotein receptor \\
\hline Leuk 4 & 4-series leukotrienes \\
\hline LOX & Lipoxygenase \\
\hline LPC & Lysophosphatidylcholine \\
\hline LPC-DHA & Lysophosphatidylcholine-Docosahexaenoic acid \\
\hline LPC-PUFAs & Lysophosphatidylcholine-Polyunsaturated fatty acids \\
\hline LPL & Lipoprotein lipase \\
\hline LTs & Leukotrienes \\
\hline $\mathrm{LTB}_{4}$ & Leukotriene $\mathrm{B}_{4}$ \\
\hline $\mathrm{LTB}_{5}$ & Leukotriene $\mathrm{B}_{5}$ \\
\hline $\mathrm{LTC}_{4}$ & Leukotriene $\mathrm{C}_{4}$ \\
\hline $\mathrm{LTC}_{5}$ & Leukotriene $\mathrm{C}_{5}$ \\
\hline $\mathrm{LTD}_{4}$ & Leukotriene $\mathrm{D}_{4}$ \\
\hline $\mathrm{LTD}_{5}$ & Leukotriene $\mathrm{D}_{5}$ \\
\hline $\mathrm{LXA}_{4}$ & Lipoxin $\mathrm{A}_{4}$ \\
\hline MAPK & Mitogen-Activated Protein Kinases \\
\hline Mfsd2a & Major facilitator superfamily domain-containing protein 2 \\
\hline MMP-9 & Matrix metalloproteinase- 9 \\
\hline mPGES-1 & Microsomal prostaglandin E synthase-1 \\
\hline mRNA & Messenger Ribonucleic acid \\
\hline MTT & 3-(4,5-dimethylthiazol-2-yl)-2,5-diphenyltetrazolium bromide \\
\hline NE-DHA & Non esterified-Docosahexaenoic acid \\
\hline NE-PUFAs & Non esterified-Polyunsaturated fatty acids \\
\hline NFATC1 & Nuclear factor of activated T cells 1 \\
\hline NSCs & Neuronal stem cells \\
\hline 17-ODYA & 17-octadecynoic acid \\
\hline p27 & Cyclin-dependent kinase inhibitor 1B \\
\hline p38 & Mitogen-activated protein kinase \\
\hline p53 & Tumor protein p53 \\
\hline
\end{tabular}




\begin{tabular}{|c|c|}
\hline PARP & Poly (ADP-ribose) polymerase \\
\hline PCNA & Proliferating cell nuclear antigen \\
\hline $\mathrm{pERK} 1 / 2$ & Extracellular signal-regulated kinase $1 / 2$ \\
\hline PGEs & Prostaglandins \\
\hline $\mathrm{PGD}_{2}$ & Prostaglandin $\mathrm{D}_{2}$ \\
\hline $\mathrm{PGE}_{1}$ & Prostaglandin $\mathrm{E}_{1}$ \\
\hline $\mathrm{PGE}_{2}$ & Prostaglandin $\mathrm{E}_{2}$ \\
\hline $\mathrm{PGE}_{3}$ & Prostaglandin $E_{3}$ \\
\hline $\mathrm{PGF}_{2 \alpha}$ & Prostaglandin $\mathrm{F}_{2 \alpha}$ \\
\hline $\mathrm{PGF}_{3}$ & Prostaglandin $\mathrm{F}_{3}$ \\
\hline PGES & Prostaglandin E synthase \\
\hline PI3K & Phosphatidylinositol 3-kinase \\
\hline PKA & Protein kinase A \\
\hline PKC & Protein kinase $\mathrm{C}$ \\
\hline PUFAs & Polyunsaturated fatty acids \\
\hline-3 PUFAs & Omega-3-polyunsaturated fatty acids \\
\hline-6 PUFAs & Omega-6-polyunsaturated fatty acids \\
\hline Sp1 & Specificity protein 1 \\
\hline Sp3 & Specificity protein 3 \\
\hline ROS & Reactive oxygen species \\
\hline 17RS-HpDHA & 17S-hydroxy-containing docosanoids \\
\hline sEH & Soluble Epoxy-Hydrolase \\
\hline TNF- $\alpha$ & Tumor necrosis factor-alpha \\
\hline TPA & 12-O-tetradecanoylphorbol-13-acetate \\
\hline TUNEL & Terminal deoxynucleotidyl transferase (TdT) dUTP Nick-End Labeling \\
\hline TXs & Thromboxanes \\
\hline $\mathrm{TXA}_{2}$ & Thromboxane $\mathrm{A}_{2}$ \\
\hline $\mathrm{TXA}_{3}$ & Thromboxane $\mathrm{A}_{3}$ \\
\hline $\mathrm{TXB}_{2}$ & Thromboxane $\mathrm{B}_{2}$ \\
\hline VEGF & Vascular Endothelial Growth Factor \\
\hline $\mathrm{WHO}$ & World Health Organization \\
\hline
\end{tabular}

\section{References}

1. De Robles, P.; Fiest, K.M.; Frolkis, A.D.; Pringsheim, T.; Atta, C.; Germaine-Smith, C.S.; Day, L.; Lam, D.; Jette, N. The worldwide incidence and prevalence of primary brain tumors: A systematic review and meta-analysis. Neuro-Oncology 2014, 17, 776-783. [CrossRef] [PubMed]

2. International Agency for Research on Cancer. All Cancers-WHO 2018. In All Cancers 2018; International Agency for Research on Cancer: Lyon, France, 2018; Volume 876, p. 2.

3. Ostrom, Q.T.; Gittleman, H.; Truitt, G.; Boscia, A.; Kruchko, C.; Barnholtz-Sloan, J.S. CBTRUS Statistical Report: Primary Brain and Other Central Nervous System Tumors Diagnosed in the United States in 2011-2015. Neuro-Oncol. 2018, 20, iv1-iv86. [CrossRef] [PubMed]

4. Shah, V.; Kochar, P. Brain Cancer: Implication to Disease, Therapeutic Strategies and Tumor Targeted Drug Delivery Approaches. Recent Pat. Anti. Cancer Drug Discov. 2018, 13, 70-85. [CrossRef] [PubMed]

5. Tandel, G.S.; Biswas, M.; Kakde, O.G.; Tiwari, A.; Suri, H.S.; Turk, M.; Laird, J.R.; Asare, C.K.; Ankrah, A.A.; Khanna, N.N.; et al. A Review on a Deep Learning Perspective in Brain Cancer Classification. Cancers 2019, 11, 111. [CrossRef]

6. Lapointe, S.; Perry, A.; Butowski, N. Primary brain tumours in adults. Lancet 2018, 392, 432-446. [CrossRef]

7. Newton, H.B. Primary brain tumors: Review of etiology, diagnosis and treatment. Am. Fam. Physician 1994, 49, 787-797.

8. Chan, M.-Y.; Teo, W.-Y.; Seow, W.-T.; Tan, A.-M. Epidemiology, management and treatment outcome of medulloblastoma in singapore. Ann. Acad. Med. Singap. 2007, 36, 314-318.

9. Brain Cancer \& Brain Tumor: Symptoms \& More, Cleveland Clinic. Available online: https://my. clevelandclinic.org/health/articles/6149-brain-cancer-brain-tumor-adult (accessed on 23 November 2019). 
10. Fisher, J.L.; Schwartzbaum, J.; Wrensch, M.; Berger, M.S. Evaluation of Epidemiologic Evidence for Primary Adult Brain Tumor Risk Factors Using Evidence-Based Medicine. Prog. Neurol. Surg. 2006, 19, 54-79. [CrossRef]

11. Karipidis, K.; Benke, G.; Sim, M.R.; Kauppinen, T.; Giles, G.G. Occupational exposure to ionizing and non-ionizing radiation and risk of glioma. Occup. Med. 2007, 57, 518-524. [CrossRef]

12. Farrell, C.J.; Plotkin, S.R. Genetic Causes of Brain Tumors: Neurofibromatosis, Tuberous Sclerosis, von Hippel-Lindau, and Other Syndromes. Neurol. Clin. 2007, 25, 925-946. [CrossRef]

13. Di Lorenzo, R.; Ahluwalia, M.S. Targeted therapy of brain metastases: Latest evidence and clinical implications. Ther. Adv. Med. Oncol. 2017, 9, 781-796. [CrossRef] [PubMed]

14. Stelzer, K.J. Epidemiology and prognosis of brain metastases. Surg. Neurol. Int. 2013, 4, S192-S202. [CrossRef] [PubMed]

15. Nussbaum, E.S.; Djalilian, H.R.; Cho, K.H.; Hall, W.A. Brain metastases. Histology, multiplicity, surgery, and survival. Cancer 1996, 78, 1781-1788. [CrossRef]

16. DeAngelis, L.M. Anaplastic Glioma: How to Prognosticate Outcome and Choose a Treatment Strategy. J. Clin. Oncol. 2009, 27, 5861-5862. [CrossRef] [PubMed]

17. Kebudi, R.; Ayan, I.; Görgün, Ö.; Agaoglu, F.Y.; Vural, S.; Darendeliler, E. Brain metastasis in pediatric extracranial solid tumors: Survey and literature review. J. Neuro-Oncol. 2005, 71, 43-48. [CrossRef]

18. Qiu, J.; Shi, Z.; Jiang, J. Cyclooxygenase-2 in glioblastoma multiforme. Drug Discov. Today 2017, 22, 148-156. [CrossRef]

19. Stupp, R.; Mason, W.P.; Bent, M.J.V.D. Radiotherapy plus Concomitant and Adjuvant Temozolomide for Glioblastoma. N. Engl. J. Med. 2005, 27, 15-16. [CrossRef]

20. Imperato, J.P.; Paleologos, N.A.; Vick, N.A. Effects of treatment on long-term survivors with malignant astrocytomas. Ann. Neurol. 1990, 28, 818-822. [CrossRef]

21. Laramore, G.; Martz, K.; Nelson, J.; Griffin, T.; Chang, C.; Horton, J. Radiation therapy oncology group (rtog) survival data on anaplastic astrocytomas of the brain: Does a more aggressive form of treatment adversely impact survival? Int. J. Radiat. Oncol. 1989, 17, 1351-1356. [CrossRef]

22. Abbott, N.J.; Patabendige, A.; Dolman, D.E.; Yusof, S.R.; Begley, D.J. Structure and function of the blood-brain barrier. Neurobiol. Dis. 2010, 37, 13-25. [CrossRef]

23. Lee, G.S.; Pan, Y.; Scanlon, M.J.; Porter, C.J.H.; Nicolazzo, J.A. Fatty Acid-Binding Protein 5 Mediates the Uptake of Fatty Acids, but not Drugs, Into Human Brain Endothelial Cells. J. Pharm. Sci. 2018, 107, 1185-1193. [CrossRef]

24. Bernardi, A.; Braganhol, E.; Jäger, E.; Figueiró, F.; Edelweiss, M.I.; Pohlmann, A.R.; Guterres, S.S.; Battastini, A.M. Indomethacin-loaded nanocapsules treatment reduces in vivo glioblastoma growth in a rat glioma model. Cancer Lett. 2009, 281, 53-63. [CrossRef] [PubMed]

25. Brigger, I.; Dubernet, C.; Couvreur, P. Nanoparticles in cancer therapy and diagnosis. Adv. Drug Deliv. Rev. 2002, 54, 631-651. [CrossRef]

26. Calder, P.C. Functional Roles of Fatty Acids and Their Effects on Human Health. J. Parenter. Enter. Nutr. 2015, 39, 18S-32S. [CrossRef] [PubMed]

27. Burr, G.O.; Burr, M.M. A new deficiency disease produced by the rigid exclusion of fat from the diet. Nutr. Rev. 2009, 31, 148-149. [CrossRef] [PubMed]

28. Spector, A.A.; Kim, H.Y. Discovery of essential fatty acids. J. Lipid Res. 2014, 56, 11-21. [CrossRef]

29. Moghadasian, M.H. Advances in Dietary Enrichment with N-3 Fatty Acids. Crit. Rev. Food Sci. Nutr. 2008, 48, 402-410. [CrossRef]

30. Kim, D.E.; Shang, X.; Assefa, A.; Keum, Y.S.; Saini, R.K. Metabolite profiling of green, green/red, and red lettuce cultivars: Variation in health beneficial compounds and antioxidant potential. Food Res. Int. 2018, 105, 361-370. [CrossRef]

31. Doughman, S.D.; Krupanidhi, S.; Sanjeevi, C.B. Omega-3 fatty acids for nutrition and medicine: Considering microalgae oil as a vegetarian source of EPA and DHA. Curr. Diabetes Rev. 2007, 3, 198-203. [CrossRef]

32. Sontrop, J.M.; Campbell, M.K. $\omega-3$ polyunsaturated fatty acids and depression: A review of the evidence and a methodological critique. Prev. Med. 2006, 42, 4-13. [CrossRef]

33. Parker, G. Omega-3 Fatty Acids and Mood Disorders. Am. J. Psychiatry 2006, 163, 969-978. [CrossRef] 
34. Buddhachat, K.; Siengdee, P.; Chomdej, S.; Soontornvipart, K.; Nganvongpanit, K. Effects of different omega-3 sources, fish oil, krill oil, and green-lipped mussel against cytokine-mediated canine cartilage degradation. Vitr. Cell. Dev. Boil. Anim. 2017, 53, 448-457. [CrossRef] [PubMed]

35. Smith, W.L.; Urade, Y.; Jakobsson, P.J. Enzymes of the Cyclooxygenase Pathways of Prostanoid Biosynthesis. Chem. Rev. 2011, 111, 5821-5865. [CrossRef] [PubMed]

36. Sutherland, M.; Shankaranarayanan, P.; Schewe, T.; Nigam, S. Evidence for the presence of phospholipid hydroperoxide glutathione peroxidase in human platelets: Implications for its involvement in the regulatory network of the 12-lipoxygenase pathway of arachidonic acid metabolism. Biochem. J. 2000, 353, 91-100. [CrossRef]

37. Feltenmark, S.; Gautam, N.; Brunnström, Å.; Griffiths, W.J.; Backman, L.; Edenius, C.; Lindbom, L.; Björkholm, M.; Claesson, H.-E. Eoxins are proinflammatory arachidonic acid metabolites produced via the 15-lipoxygenase-1 pathway in human eosinophils and mast cells. Proc. Natl. Acad. Sci. USA 2008, 105, 680-685. [CrossRef]

38. Yuan, D.; Zou, Q.; Yu, T.; Song, C.; Huang, S.; Chen, S.; Ren, Z.; Xu, A. Ancestral genetic complexity of arachidonic acid metabolism in Metazoa. Biochim. Biophys. Acta (BBA) Mol. Cell Boil. Lipids 2014, 1841, 1272-1284. [CrossRef]

39. Das, U.N. Essential fatty acids: Biochemistry, physiology and pathology. Biotechnol. J. 2006, 1, 420-439. [CrossRef]

40. DeFilippis, A.P.; Sperling, L.S. Understanding omega-3's. Am. Hear. J. 2006, 151, 564-570. [CrossRef]

41. Wei, Y.; Zou, D.; Cao, D.; Xie, P. Association between processed meat and red meat consumption and risk for glioma: A meta-analysis from 14 articles. Nutrition 2015, 31, 45-50. [CrossRef]

42. Holick, C.N.; Giovannucci, E.L.; Rosner, B.; Stampfer, M.J.; Michaud, M.S. Prospective study of intake of fruit, vegetables, and carotenoids and the risk of adult glioma. Am. J. Clin. Nutr. 2007, 85, 877-886. [CrossRef]

43. Lian, W.; Wang, R.; Xing, B.; Yao, Y. Fish intake and the risk of brain tumor: A meta-analysis with systematic review. Nutr. J. 2017, 16, 1. [CrossRef] [PubMed]

44. Huerta-Yépez, S.; Tirado-Rodriguez, A.B.; Hankinson, O. Papel de las dietas ricas en omega-3 y omega-6 en el desarrollo del cancer. Med. Bull. Child. Hosp. Mex. 2016, 73, 446-456.

45. Simopoulos, A.P. An increase in the Omega-6/Omega-3 fatty acid ratio increases the risk for obesity. Nutrients 2016, 8, 128. [CrossRef] [PubMed]

46. Sekikawa, A.; Steingrimsdottir, L.; Ueshima, H.; Shin, C.; Curb, J.D.; Evans, R.W.; Hauksdottir, A.M.; Kadota, A.; Choo, J.; Masaki, K.; et al. Serum levels of marine-derived n-3 fatty acids in Icelanders, Japanese, Koreans, and Americans-a descriptive epidemiologic study. Prostaglandins Leukot. Essent. Fat. Acids 2012, 87, 11-16. [CrossRef]

47. Stark, K.D.; Van Elswyk, M.; Higgins, M.R.; Weatherford, C.A.; Salem, N. Global survey of the omega-3 fatty acids, docosahexaenoic acid and eicosapentaenoic acid in the blood stream of healthy adults. Prog. Lipid Res. 2016, 63, 132-152. [CrossRef]

48. Blasbalg, T.L.; Hibbeln, J.R.; Ramsden, C.E.; Majchrzak, S.F.; Rawlings, R.R. Changes in consumption of omega-3 and omega-6 fatty acids in the United States during the 20th century. Am. J. Clin. Nutr. 2011, 93, 950-962. [CrossRef]

49. De Turco, E.B.; Gordon, W.C.; Peyman, G.A.; Bazan, N.G. Preferential uptake and metabolism of docosahexaenoic acid in membrane phospholipids from rod and cone photoreceptor cells of human and monkey retinas. J. Neurosci. Res. 1990, 27, 522-532. [CrossRef]

50. Ferdouse, A.; Leng, S.; Winter, T.; Aukema, H.M. The Brain Oxylipin Profile Is Resistant to Modulation by Dietary n-6 and n-3 Polyunsaturated Fatty Acids in Male and Female Rats. Lipids 2019, 54, 67-80. [CrossRef]

51. Mitchell, R.W.; On, N.H.; Del Bigio, M.R.; Miller, D.W.; Hatch, G.M. Fatty acid transport protein expression in human brain and potential role in fatty acid transport across human brain microvessel endothelial cells. J. Neurochem. 2011, 117, 735-746. [CrossRef]

52. Chouinard-Watkins, R.; Lacombe, R.S.; Bazinet, R.P. Mechanisms regulating brain docosahexaenoic acid uptake. Curr. Opin. Clin. Nutr. Metab. Care 2018, 21, 71-77. [CrossRef]

53. Ramsden, C.E.; Hennebelle, M.; Schuster, S.; Keyes, G.S.; Johnson, C.D.; Kirpich, I.A.; Dahlen, J.E.; Horowitz, M.S.; Zamora, D.; Feldstein, A.E.; et al. Effects of diets enriched in linoleic acid and its peroxidation products on brain fatty acids, oxylipins, and aldehydes in mice. Biochim. Biophys. Acta (BBA) Mol. Cell Boil. Lipids 2018, 1863, 1206-1213. [CrossRef] 
54. Su, K.P. Biological Mechanism of Antidepressant Effect of Omega-3 Fatty Acids: How Does Fish Oil Act as a 'Mind-Body Interface'? Neurosignals 2009, 17, 144-152. [CrossRef] [PubMed]

55. Weisinger, H.S.; Vingrys, A.J.; Sinclair, A.J. Dietary manipulation of long-chain polyunsaturated fatty acids in the retina and brain of guinea pigs. Lipids 1995, 30, 471-473. [CrossRef] [PubMed]

56. Nariai, T.; DeGeorge, J.J.; Greig, N.H.; Genka, S.; Rapoport, S.I.; Purdon, A.D. Differences in rates of incorporation of intravenously injected radiolabeled fatty acids into phospholipids of intracerebrally implanted tumor and brain in awake rats. Clin. Exp. Metastasis 1994, 12, 213-225. [CrossRef]

57. Costantini, L.; Molinari, R.; Farinon, B.; Merendino, N. Impact of Omega-3 Fatty Acids on the Gut Microbiota. Int. J. Mol. Sci. 2017, 18, 2645. [CrossRef]

58. Pawełczyk, T.; Grancow-Grabka, M.; Kotlicka-Antczak, M.; Trafalska, E.; Gębski, P.; Szemraj, J.; Żurner, N.; Pawełczyk, A. Omega-3 fatty acids in first-episode schizophrenia-A randomized controlled study of efficacy and relapse prevention (OFFER): Rationale, design, and methods. BMC Psychiatry 2015, 15, 97. [CrossRef] [PubMed]

59. Obermeier, B.; Daneman, R.; Ransohoff, R.M. Development, maintenance and disruption of the blood-brain barrier. Nat. Med. 2013, 19, 1584-1596. [CrossRef]

60. Ochiai, Y.; Uchida, Y.; Ohtsuki, S.; Tachikawa, M.; Aizawa, S.; Terasaki, T. The blood-brain barrier fatty acid transport protein 1 (FATP1/SLC27A1) supplies docosahexaenoic acid to the brain, and insulin facilitates transport. J. Neurochem. 2017, 141, 400-412. [CrossRef]

61. Nguyen, L.N.; Ma, D.; Shui, G.; Wong, P.; Cazenave-Gassiot, A.; Zhang, X.; Wenk, M.R.; Goh, E.L.K.; Silver, D.L. Mfsd2a is a transporter for the essential omega-3 fatty acid docosahexaenoic acid. Nature 2014, 509, 503-506. [CrossRef]

62. Lee, G.S.; Kappler, K.; Porter, C.J.H.; Scanlon, M.J.; Nicolazzo, J.A. Fatty Acid Binding Proteins Expressed at the Human Blood-Brain Barrier Bind Drugs in an Isoform-Specific Manner. Pharm. Res. 2015, 32, 3432-3446. [CrossRef]

63. Pan, Y.; Scanlon, M.J.; Owada, Y.; Yamamoto, Y.; Porter, C.J.H.; Nicolazzo, J.A. Fatty Acid-Binding Protein 5 Facilitates the Blood-Brain Barrier Transport of Docosahexaenoic Acid. Mol. Pharm. 2015, 12, 4375-4385. [CrossRef] [PubMed]

64. Murphy, E. Blood-brain barrier and brain fatty acid uptake: Role of arachidonic acid and PGE2. J. Neurochem. 2015, 135, 845-848. [CrossRef] [PubMed]

65. Veerkamp, J.H.; Zimmerman, A.W. Fatty Acid-Binding Proteins of Nervous Tissue. J. Mol. Neurosci. 2001, 16, 133-142. [CrossRef]

66. Murphy, E.J.; Owada, Y.; Kitanaka, N.; Kondo, H.; Glatz, J.F.C. Brain Arachidonic Acid Incorporation Is Decreased in Heart Fatty Acid Binding Protein Gene-Ablated Mice. Biochemistry 2005, 44, 6350-6360. [CrossRef]

67. Liu, R.Z.; Mita, R.; Beaulieu, M.; Gao, Z.; Godbout, R. Fatty acid binding proteins in brain development and disease. Int. J. Dev. Boil. 2010, 54, 1229-1239. [CrossRef] [PubMed]

68. Liu, J.W.; Almaguel, F.G.; Bu, L.; De Leon, D.D.; De Leon, M. Expression of E-FABP in PC12 cells increases neurite extension during differentiation: Involvement of n-3 and n-6 fatty acids. J. Neurochem. 2008, 106, 2015-2029. [CrossRef] [PubMed]

69. Xu, L.Z.; Sánchez, R.; Sali, A.; Heintz, N. Ligand Specificity of Brain Lipid-binding Protein. J. Boil. Chem. 1996, 271, 24711-24719. [CrossRef]

70. Fukumoto, K.-I.; Takagi, N.; Yamamoto, R.; Moriyama, Y.; Takeo, S.; Tanonaka, K. Prostanoid EP1 receptor antagonist reduces blood-brain barrier leakage after cerebral ischemia. Eur. J. Pharmacol. 2010, 640, 82-86. [CrossRef]

71. Jiang, J.; Dingledine, R.; And, J.J. Prostaglandin receptor EP2 in the crosshairs of anti-inflammation, anti-cancer, and neuroprotection. Trends Pharmacol. Sci. 2013, 34, 413-423. [CrossRef]

72. Liu, J.J.; Green, P.; Mann, J.J.; Rapoport, S.I.; Sublette, M.E. Pathways of polyunsaturated fatty acid utilization: Implications for brain function in neuropsychiatric health and disease. Brain Res. 2014, 1597, 220-246. [CrossRef]

73. Gurtovenko, A.A.; Vattulainen, I. Molecular Mechanism for Lipid Flip-Flops. J. Phys. Chem. B 2007, 111, 13554-13559. [CrossRef] [PubMed]

74. Banks, W.A. Characteristics of compounds that cross the blood-brain barrier. BMC Neurol. 2009, 9, 5-9. [CrossRef] [PubMed] 
75. Shie, F.-S.; Breyer, R.M.; Montine, T.J. Microglia Lacking E Prostanoid Receptor Subtype 2 Have Enhanced A $\beta$ Phagocytosis yet Lack A $\beta$-Activated Neurotoxicity. Am. J. Pathol. 2005, 166, 1163-1172. [CrossRef]

76. Payner, T.; Leaver, H.A.; Knapp, B.; Whittle, I.R.; Trifan, O.C.; Miller, S.; Rizzo, M.T. Microsomal prostaglandin E synthase-1 regulates human glioma cell growth via prostaglandin E2-dependent activation of type II protein kinase A. Mol. Cancer Ther. 2006, 5, 1817-1826. [CrossRef] [PubMed]

77. Bylund, J.; Zhang, C.; Harder, D.R. Identification of a novel cytochrome P450, CYP4X1, with unique localization specific to the brain. Biochem. Biophys. Res. Commun. 2002, 296, 677-684. [CrossRef]

78. Guo, A.M.; Sheng, J.; Scicli, G.M.; Arbab, A.S.; Lehman, N.L.; Edwards, P.A.; Falck, J.R.; Roman, R.J.; Scicli, A.G. Expression of CYP4A1 in U251 human glioma cell induces hyperproliferative phenotype in vitro and rapidly growing tumors in vivo. J. Pharmacol. Exp. Ther. 2008, 327, 10-19. [CrossRef]

79. Shono, T.; Tofilon, P.J.; Bruner, J.M.; Owolabi, O.; Lang, F.F. Cyclooxygenase-2 expression in human gliomas: Prognostic significance and molecular correlations. Cancer Res. 2001, 61, 4375-4381.

80. Svensson, C.I.; Zattoni, M.; Serhan, C.N. Lipoxins and aspirin-triggered lipoxin inhibit inflammatory pain processing. J. Exp. Med. 2007, 204, 245-252. [CrossRef]

81. Serhan, C.N.; Hong, S.; Gronert, K.; Colgan, S.P.; Devchand, P.R.; Mirick, G.; Moussignac, R.L. Resolvins: A family of bioactive products of omega-3 fatty acid transformation circuits initiated by aspirin treatment that counter proinflammation signals. J. Exp. Med. 2002, 196, 1025-1037. [CrossRef]

82. Hong, S.; Gronert, K.; Devchand, P.R.; Moussignac, R.L.; Serhan, C.N. Novel docosatrienes and 17S-resolvins generated from docosahexaenoic acid in murine brain, human blood, and glial cells. Autacoids in anti-inflammation. J. Biol. Chem. 2003, 278, 14677-14687. [CrossRef]

83. Ferreira, M.T.; Gomes, R.N.; Panagopoulos, A.T.; De Almeida, F.G.; Veiga, J.C.E.; Colquhoun, A. Opposing roles of PGD 2 in GBM. Prostaglandins Other Lipid Mediat. 2018, 134, 66-76. [CrossRef]

84. Authier, A.; Farrand, K.J.; Broadley, K.W.; Ancelet, L.R.; Hunn, M.K.; Stone, S.; McConnell, M.J.; Hermans, I.F. Enhanced immunosuppression by therapy-exposed glioblastoma multiforme tumor cells. Int. J. Cancer 2014, 136, 2566-2578. [CrossRef] [PubMed]

85. Hanahan, D.; Weinberg, R.A. Hallmarks of Cancer: The Next Generation. Cell 2011, 144, 646-674. [CrossRef] [PubMed]

86. Elsherbiny, M.; Chen, H.; Emara, M.; Godbout, R. $\omega-3$ and $\omega-6$ Fatty Acids Modulate Conventional and Atypical Protein Kinase C Activities in a Brain Fatty Acid Binding Protein Dependent Manner in Glioblastoma Multiforme. Nutrients 2018, 10, 454. [CrossRef] [PubMed]

87. Leaver, H.; Bell, H.; Rizzo, M.; Ironside, J.W.; Gregor, A.; Wharton, S.; Whittle, I. Antitumour and pro-apoptotic actions of highly unsaturated fatty acids in glioma. Prostaglandins Leukot. Essent. Fat. Acids 2002, 66, 19-29. [CrossRef]

88. Matsuo, M.; Yoshida, N.; Zaitsu, M.; Ishii, K.; Hamasaki, Y. Inhibition of human glioma cell growth by a PHS-2 inhibitor, NS398, and a prostaglandin E receptor subtype EP1-selective antagonist, SC51089. J. Neuro-Oncol. 2004, 66, 285-292. [CrossRef]

89. Brocard, E.; Oizel, K.; Lalier, L.; Pecqueur, C.; Paris, F.; Vallette, F.M.; Oliver, L. Radiation-induced PGE2 sustains human glioma cell growth and survival through EGF signaling. Oncotarget 2015, 6, 6840-6849. [CrossRef]

90. Cook, P.J.; Thomas, R.; Kingsley, P.J.; Shimizu, F.; Montrose, D.C.; Marnett, L.J.; Tabar, V.S.; Dannenberg, A.J.; Benezra, R. Cox-2-derived PGE2induces Id1-dependent radiation resistance and self-renewal in experimental glioblastoma. Neuro-Oncol. 2016, 18, 1379-1389. [CrossRef]

91. Gomes, R.N.; Colquhoun, A. E series prostaglandins alter the proliferative, apoptotic and migratory properties of T98G human glioma cells in vitro. Lipids Heal. Dis. 2012, 11, 171. [CrossRef]

92. Wada, K.; Arita, M.; Nakajima, A.; Katayama, K.; Kudo, C.; Kamisaki, Y.; Serhan, C.N. Leukotriene B 4 and lipoxin A 4 are regulatory signals for neural stem cell proliferation and differentiation. FASEB J. 2006, 20, 1785-1792. [CrossRef]

93. Kim, S.; Jing, K.; Shin, S.; Jeong, S.; Han, S.H.; Oh, H.; Yoo, Y.S.; Han, J.; Jeon, Y.J.; Heo, J.Y.; et al. $\omega 3$-polyunsaturated fatty acids induce cell death through apoptosis and autophagy in glioblastoma cells: In vitro and in vivo. Oncol. Rep. 2018, 39, 239-246. [CrossRef] [PubMed]

94. Vartak, S.; Robbins, M.E.; Spector, A.A. Polyunsaturated fatty acids increase the sensitivity of 36B10 rat astrocytoma cells to radiation-induced cell kill. Lipids 1997, 32, 283-292. [CrossRef] [PubMed] 
95. Das, U.N.; Huang, Y.S.; Bégin, M.E.; Ells, G.; Horrobin, D.F. Uptake and distribution of cis-unsaturated fatty acids and their effect on free radical generation in normal and tumor cells in vitro. Free Radic. Boil. Med. 1987, 3, 9-14. [CrossRef]

96. Liu, Q.; Tan, W.; Che, J.; Yuan, D.; Zhang, L.; Sun, Y.; Yue, X.; Xiao, L.; Jin, Y. 12-HETE facilitates cell survival by activating the integrin-linked kinase/NF-кB pathway in ovarian cancer. Cancer Manag. Res. 2018, 10, 5825-5838. [CrossRef]

97. Bell, H.S.; Wharton, S.B.; Leaver, H.A.; Whittle, I.R. Effects of N-6 essential fatty acids on glioma invasion and growth: Experimental studies with glioma spheroids in collagen gels. J. Neurosurg. 1999, 91, 989-996. [CrossRef]

98. Lalier, L.; Cartron, P.F.; Pedelaborde, F.; Olivier, C.; Loussouarn, D.; Martin, S.A.; Meflah, K.; Menanteau, J.; Vallette, F.M. Increase in PGE2 biosynthesis induces a Bax dependent apoptosis correlated to patients' survival in glioblastoma multiforme. Oncogene 2007, 26, 4999-5009. [CrossRef] [PubMed]

99. Wang, W.; Zhu, J.; Lyu, F.; Panigrahy, D.; Ferrara, K.W.; Hammock, B.; Zhang, G. w-3 polyunsaturated fatty acids-derived lipid metabolites on angiogenesis, inflammation and cancer. Prostaglandins Other Lipid Mediat. 2014, 113, 13-20. [CrossRef] [PubMed]

100. Xu, K.; Chang, C.M.; Gao, H.; Shu, H.K.G. Epidermal growth factor-dependent cyclooxygenase-2 induction in gliomas requires protein kinase C- $\delta$. Oncogene 2009, 28, 1410-1420. [CrossRef] [PubMed]

101. Wang, F.; Bhat, K.; Doucette, M.; Zhou, S.; Gu, Y.; Law, B.; Liu, X.; Wong, E.T.; Kang, J.X.; Hsieh, T.C.; et al. Docosahexaenoic acid (DHA) sensitizes brain tumor cells to etoposide-induced apoptosis. Curr. Mol. Med. 2011, 11, 503-511. [CrossRef] [PubMed]

102. Xu, K.; Shu, H.K.G. EGFR activation results in enhanced cyclooxygenase-2 expression through p38 mitogen-activated protein kinase-dependent activation of the SP1/SP3 transcription factors in human gliomas. Cancer Res. 2007, 67, 6121-6129. [CrossRef]

103. Chen, P.; Guo, M.; Wygle, D.; Edwards, P.A.; Falck, J.R.; Roman, R.J.; Scicli, A.G. Inhibitors of Cytochrome P450 4A Suppress Angiogenic Responses. Am. J. Pathol. 2005, 166, 615-624. [CrossRef]

104. Alkayed, N.J.; Narayanan, J.; Gebremedhin, D.; Medhora, M.; Roman, R.J.; Harder, D.R. Molecular Characterization of an Arachidonic Acid Epoxygenase in Rat Brain Astrocytes. Stroke 1996, 27, 971-979. [CrossRef] [PubMed]

105. Zhang, C.; Harder, D.R. Cerebral capillary endothelial cell mitogenesis and morphogenesis induced by astrocytic epoxyeicosatrienoic Acid. Stroke 2002, 33, 2957-2964. [CrossRef] [PubMed]

106. Zagorac, A.; Jakovcevic, D.; Gebremedhin, D.; Harder, D.R. Antiangiogenic Effect of Inhibitors of Cytochrome P450 on Rats with Glioblastoma Multiforme. Br. J. Pharmacol. 2008, 28, 1431-1439. [CrossRef] [PubMed]

107. Mita, R.; Beaulieu, M.J.; Field, C.; Godbout, R. Brain Fatty Acid-binding Protein and $\omega-3 / \omega-6$ Fatty Acids: Mechanistic insight into malignant glioma cell migration. J. Biol. Chem. 2010, 285, 37005-37015. [CrossRef] [PubMed]

108. Zou, Y.; Watters, A.; Cheng, N.; Perry, C.E.; Xu, K.; Alicea, G.M.; Parris, J.L.; Baraban, E.; Ray, P.; Nayak, A.; et al. Polyunsaturated Fatty Acids from Astrocytes Activate PPAR $\gamma$ Signaling in Cancer Cells to Promote Brain Metastasis. Cancer Discov. 2019, 9, 1720-1735. [CrossRef] [PubMed]

109. Denkins, Y.; Kempf, D.; Ferniz, M.; Nileshwar, S.; Marchetti, D. Role of $\omega-3$ polyunsaturated fatty acids on cyclooxygenase-2 metabolism in brain-metastatic melanoma. J. Lipid Res. 2005, 4, 1278-1284. [CrossRef]

110. Chiu, W.T.; Shen, S.C.; Chow, J.M.; Lin, C.W.; Shia, L.T.; Chen, Y.C. Contribution of reactive oxygen species to migration/invasion of human glioblastoma cells U87 via ERK-dependent COX-2/PGE2 activation. Neurobiol. Dis. 2010, 37, 118-129. [CrossRef]

111. Wang, L.; Wang, Z.; Li, J.; Zhang, W.; Ren, F.; Yue, W. NFATc1 activation promotes the invasion of U251 human glioblastoma multiforme cells through COX-2. Int. J. Mol. Med. 2015, 35, 1333-1340. [CrossRef]

112. Gomes, R.N.; Colquhoun, A. CBIO-11EFFECT OF PROSTAGLANDIN E2ON CELL MIGRATION IN U251 MG AND U87 MG HUMAN GLIOMA CELLS. Neuro-Oncology 2015, 17, v57. [CrossRef]

(C) 2020 by the authors. Licensee MDPI, Basel, Switzerland. This article is an open access article distributed under the terms and conditions of the Creative Commons Attribution (CC BY) license (http://creativecommons.org/licenses/by/4.0/). 